\title{
Penerapan HOTS untuk Memperkuat Kompetensi Mengajar Musik
}

\section{HOTS Application to Strengthen Music Teaching Competencies}

\author{
Diah Latifah \\ Universitas Pendidikan Indonesia, Bandung, Jawa Barat, Indonesia \\ diahlatifah@upi.edu
}

\begin{abstract}
Abstrak
Penelitian mengaji penerapan ketrampilan pembelajaran berorientasi HOTS bagi guru musik. Desain penelitian yang digunakan adalah DBR untuk menemukan desain mengajar musik sesuai dengan pembelajaran berorientasi HOTS. Hasil penelitian menyatakan, setelah guru mendapatkan pelatihan penerapan ketrampilan berorientasi HOTS pada pengajaran musik, guru berhasil memiliki kemampuan mengajar musik berdasar pembelajaran berorientasi HOTS, dan pola desain pembelajaran yang didapat adalah, penguatan pengetahuan dan pemahaman diterapkan melalui apresiasi musik, penerapan atau aplikasi diterapkan melalui permainan music, analisis dan kreativitas dilaksanakan melalui aransemen musik serta kegiatan guru berkolaborasi mencipta karya musik ensemble.
\end{abstract}

Kata kunci: desain mengajar musik HOTS, kompetensi mengajar music berorientasi HOTS, Penerapan model mengajar musik HOTS

\begin{abstract}
The study examines the application of HOTS oriented learning skills to music teachers. The research design used was DBR to find the design of teaching music according to HOTS oriented learning. The results of the study stated that after the teacher received training on the application of HOTS oriented skills in music teaching, the teacher managed to have the ability to teach music based on HOTS-oriented learning, and the design patterns of learning obtained were, strengthening knowledge and understanding applied through appreciation of music, or application applied through musicgames, analysis and creativity are carried out through music arrangements and the activities of the teacher collaborate to create music ensemble works.

Keywords: Application of HOTS Music Teaching Model, HOTS music teaching design, HOTS oriented music teaching competence
\end{abstract}

\section{PENDAHULUAN}

Perubahan kurikulum di Indonesia terjadi dengan cepat, hal ini berdampak pada proses pembelajaran yang dilaksanakan guru disekolah. Kurikulum mengalami revisi dua kali berturut turut pada kurun dua tahun, yaitu tahun 2016 dan 2017. Tahun 2016 mengusung HOTS hasil pemikiran Bloom yang direvisi Anderson Krathwohl. Kurikulum nasional revisi tahun 2016 menyatakan "penentuan materi yang mengarah HOTS" (Direktorat pembinaan sekolah menengah atas direktorat jenderal pendidikan dasar dan menengah kementerian pendidikan dan kebudayaan materi pokok pelatihan instruktur kurikulum, 2016) dengan pencapaian pembelajaran aspek kompetensi yang memuat kompetensi pengetahuan, ketrampilan dan sikap. Tahun 2017 revisi kurikulum nasional memiliki perubahan pencapaian, yaitu bidang kompetensi, karakter dan literasi, yang mengandung muatan kecakapan abad XXI. Kecakapan abad XXI dan HOTS pada dasarnya memiliki puncak pencapaian yang sama yaitu keativitas. Bahkan dalam pencapaian pembelajaran seni berbasis kecakapan abad XXI telah menjadi keniscayaan. Shuler 
(2011:12) "Here is how teaching the Artistic Processes model helps students master the headline 21stcentury skills in the partnership map, the so called four Cs: •Creativity, -Critical Thinking, Communication, and - Collaboration." Kebijakan ini dilaksanakan pemerintah karena terdapatnya hasil evaluasi yang menyatakan Indonesia merupakan salah satu negara yang siswa siswanya belum memiliki ketrampilan berpikir HOTS. Kusuma, Rosidin, Abdurrahman, \& Suyatna (2017:26) "Based on PISA which is reported by the Organization for Economic Co-Operation and Development (OECD), Indonesia is at 64 rank of 65 countries (OECD 2012). This result shows that most of Indonesian students still have low ability, if it is seen from cognitive aspect (knowing, applying, reasoning)". Untuk mencapai tuntutan yang setara dalam penguasaan HOTS dilaksanakan pembelajaran yang berorientasi HOTS, Kusuma, Rosidin, Abdurrahman, \& Suyatna (2017:26) mengatakan bahwa student's achievements tend so decrease on all cognitive aspects that student's ability need to be increased, particularly reasoning aspect by teaching students to develope higher order thinking.

Permasalahan terjadi tatkala guru harus mencerap beberapa perubahann kurikulum dalam waktu yang realatif singkat. Di khawatirkan masih terdapat guru yang belum memahami makna HOTS dalam implementasi pembelajaran. Gejala ini ditindak lanjuti dengan wawancara pada guru di salah satu wilayah kota administratif Kabupaten Bandung, untuk mengetahui pemahaman guru musik terhadap implementasi mengajar berorientasi HOTS dalam pembelajaran.
Hasil wawancara dengan guru musik SMA dengan inisial Enr Jhn J (guru dari wilayah Lembang Kabupaten Bandung), pada awal April 2018 menghasilkan sebuah pemaknaan; beliau sudah melaksanakan beberapa aspek yang dipaparkan dalam muatan kurikulum beroerientasi HOTS, tetapi beliau belum benar benar yakin, bagaimana penerapanya dalam dunia pembelajaran sesuai acuan kurikulum yang diimplementasikan. Beliau menyatakan, "kalau berolah "kreatif" saya sudah terapkan dalam mata pelajaran aransemen, dalam bentuk musik ansambel dan tentu saja didalamnya terdapat proses berpikir "kritis", yang dilakukan siswa saat proses mengaransemen lagu dengan saling menuangkan ide musical.

Wawancara pendahuluan pada guru mapel seni budaya bidang music menghasilkan informasi kekurang jelasan pemahaman pada proses pembelajaran berorientasi HOTS, fakta ini dilanjutkan dengan workshop penguatan ketrampilan mengajar berorientasi HOTS. Diyakini HOTS dapat diawali dengan ketidak pastian pemahaman, yang selanjutnya ditindak lanjuti dengan belajar musik berorientasi HOTS untuk mencapai keahlian yang diharapkan. Sheldon \& DeNardo (2005:41) mengatakan bahwa skill in higherorder thinking takes the student from fragile knowledge to the freedom of application and learning offered by the mastery of transfer techniques.

High order thinking skill adalah salah satu kecakapan hidup penting yang seyogyanya dimiliki putra bangsa berusia muda pada dunia kerja di abad XXI. Nalova \& Shalanyuy (2017:148) mengkonfirmasi bahwa higher order thinking skills are 
essential for the 21st century youth and the workforce. HOTS dalam kurikulum 2013 adalah penyempurnaan teori kognitif Bloom di revisi Anderson dan Krathwoll.

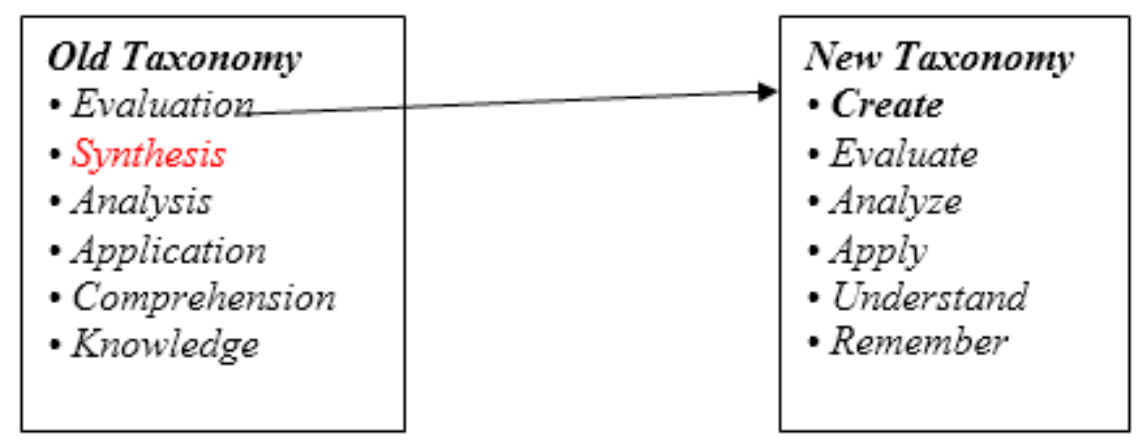

Diagram 1. Bloom_s Taxonomy Comparison: Old vs. New * (Shuler, 2011)(Bagan C1)

Dalam kurikulum tahun 2013 yang diimplementasikan di seluruh penjuru tanah air, istilahHOTS memuat enam kecakapan yang di istilahkan dengan C1 sampai C6.

$\mathrm{C} 1$ tahapan mengetahui dan mengingat,

C2 tahap memahami,

C3 tahap menerapkan,

C4 tahap menganalisis,

C5 tahap mengevaluasi dan

C6 tahap kreativitas.

Makna HOTS revisi Anderson Krathwohl dalam Hashim, Ali, \& Shamsudin (2017:1192) bahwa high order thinking skills (HOTs) as the extended use of mind to face new challenges through critical thinking and creative thinking. Both critical thinking and creative thinking are teachable and learnable components of HOTs. Paparan ini berarti HOTS dicapai melalui proses berpikir kritis dan berpikir kreatif, dan kegiatan ini sangat mungkin diajarkan pada siswa. Definisi lain menurut King, Goodson, \& Rohani (2010) adalah higher order thinking skills include critical, logical, reflective, metacognitive, and creative thinking. They are activated when individuals encounter unfamiliar problems, uncertainties, questions, or dilemmas. HOTS dimaknai sebagaiproses berpikir kritis logis, reflective, metacognitive, dan kreatif. HOTS diaktifasi saat seseorang berhadapan dengan masalah yang belum akrab, pertanyaan pertanyaan tanpa kepastian, atau dilemma-dilema.

Kompetensi musik yang dipicu oleh kegiatan kreativitas dan improvisasi dalam aransemen atau komposisi musik merupakan dua kegiatan bermuatan puncak pencapaian HOTS yaitu kreativitas. Shuler (2011:11), mengemukakan bahwa the placement of Create at the top of the new taxonomy suggests that students engaged in creating music (improvising, composing) are functioning at the highest possible levels of musical thought. Perbaikan penerapan HOTS dapat dilakukan melalui pelatihan spesifik yang dilanjutkan dengan asesmen hasil belajar music siswa. Sheldon \& DeNardo (2005:41) The improvement of proficiency in higher order thinking was shown to be attainable among teachers who weretrained in specific HOTS techniques in relationship to the assessmentof student work". HOTS adalah kemampuan pemicu ketrampilan berpikir kritis, logis, reflektif, metacognitive dan berpikirkreatif, yang pencapaianya dalam teks dan konteks pembelajaran musik dilakukan dengan pengalaman untuk mengembangkan 
kemampuan musik secara berkesinambungan bersamaan dengan kemampuan intelektual yang mengiringinya. Kembali Nalova \& Shalanyuy (2017:148) menegaskan; Higher order thinking skills include critical, logical, reflective, metacognitive, and creative thinking. Successful applications of the skills result in explanations, decisions, performances, and products that are valid within the context of available knowledge and experience and that promote continued growth in these and other intellectual skills.

Telah banyak penelitian yang menguji mengenai pengaruh Higher Order Thinking Skills (HOTS) dalam berbagai bidang baik itu bidnag musik dan bidang lainnya, seperti penelitian Small (1987), Kokkidou (2013), Spencer (2013), Wing, Piaw, \& Chang (2014), Topoğlu (2014), Collins(2014), Mohd Tajudin Assoc \& Chinnappan (2016), Dhewa Kusuma, Rosidin, \& Suyatna (2017), Hashim et al. (2017), Widana (2017), Sulaiman et al. (2017), Ping, Ahmad, Adnan, \& Hua (2017), Henninger (2018). Dengan banyaknya penelitian terdahulu dalam berbagai bidang dan berbagai negara, peneliti menjadi tertarik untuk melihat pengaruhnya untuk dilihat hubungnya dengan keterampilan musik di Indonesia.

\section{METODE PENELITIAN}

Metode penelitian yang digunakan Desain Based Research, dengan argumentasi penelitian ini berusaha menemukan model mengajar berbasis teori HOTS. Pembelajaran musik sarat dengan nuansa afektif, berdimensi proses dan hasil bermuatan afektif dengan nilai estetik. Dengan alasan ini standarisasi ketat sulit untuk diterapkan. Metode research yang bernuansa pengembangan, tetapi memiliki karakter kualitatif digunakan untuk mengembangkan model mengajar musik bagi guru SMA.

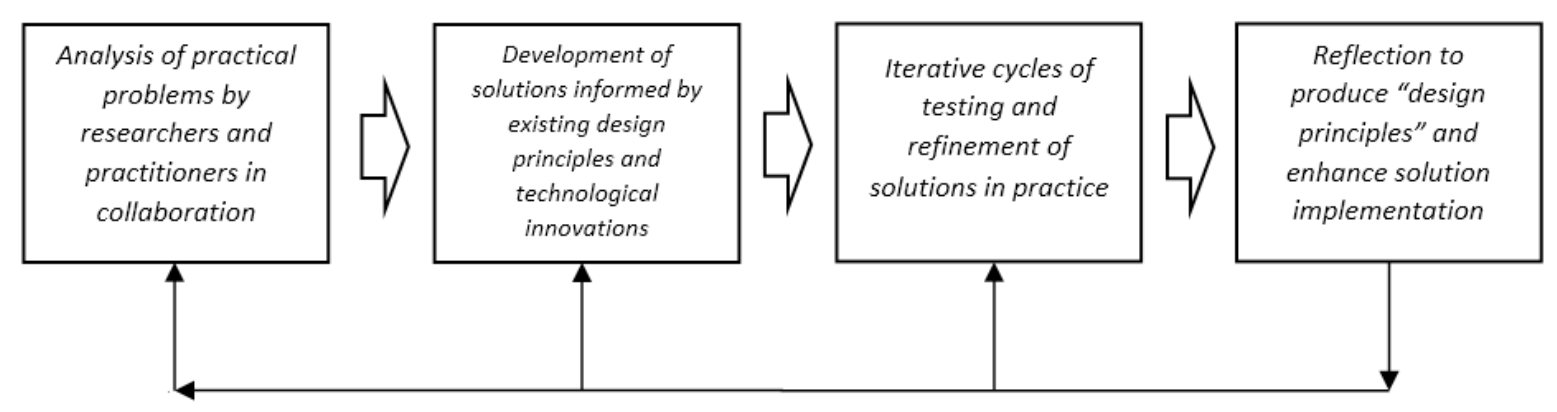

Diagram 2. Desain DBR

(Amiel \& Reeves, 2008:34)

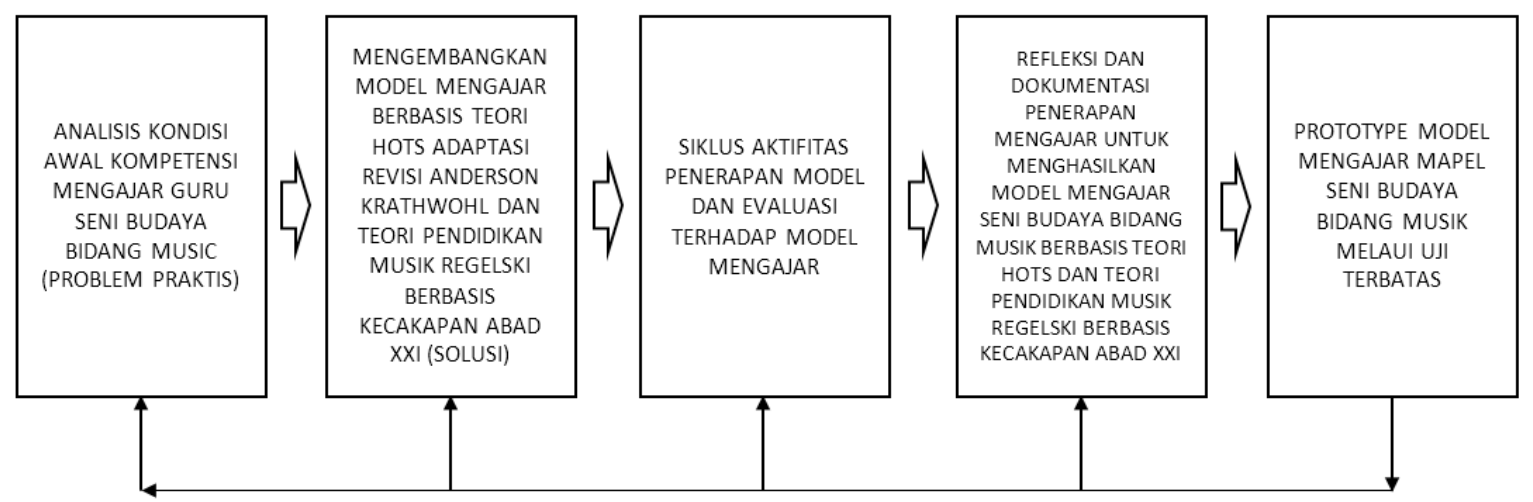

Diagram 3. Desain Tahapan DBR 
Partisipan penelitian adalah guru-guru seni budaya bidang musik. Untuk penyusunan prototype, partisipan adalah guru-guru SMA dan SMK di Bandung raya, berjumlah 20 orang yang memilih kegiatan workshop musik ritmik dan penggubahan lagu.

Uji coba terbatas akan memverifikasi model mengajar musik berbasis HOTS menghadapi para guru atau masyarakat pendukung Urban di Jawa Barat yang memiliki rasa musical etnik Sunda dan Barat. Hasil verifikasi diharapkan akan menggambarkan model mengajar dengan kinerja kreativitas mengajar para guru sesuai budaya dimana guru menetap.

Instrumen penelitian adalah: pedoman observasi untuk memindai kegiatan penerapan model mengajar, lembar assessment untuk mengevaluasi kemajuan guru dalam menerapkan model mengajar berbasis teori HOTS, lembar acuan wawancara semi terstruktur untuk mengetahui kebermaknaan penerapan model mengajar bagi guru SMA.

Pengumpulan data dilakukan melalui:

a. Analisis hasil observasi kegiatan mengajar dengan menggunakan model mengajar HOTS.

b. Analisis hasil assesment taraf kemajuan kompetensi mengajar yang didapat guru dengan menggunakan model mengajar HOTS.

c. Analisis hasil wawancara dengan guru, mengenai kebimbangan melaksanakan model mengajar HOTS yang dibekalkan kepada mereka pada studi awal penelitian.

\section{HASIL DAN PEMBAHASAN}

\subsection{Hasil}

Hasil penelitian memberikan gambaran, penerapan workshop model mengajar music berorientasi HOTS, menghasilkan kompetensi membuat kreasi music ritmik, menerapkan kurikulum 2013 berorientasi HOTS, berkreasi menggubah lagu untuk memperkuat karakter, dan melaksanakan asesmen musik berbasis kreativitas serta menyusun komposisi dan analisis aural.

Kreasi musik ritmik dilakukan dengan kreativitas eksplorasi bunyi melalui benda benda disekitar lingkungan dan body movement serta bunyi tepukan pada bagian bagian tubuh, seperti eksplorasi bunyi pada kedua belah tangan, bertepuk tangan, menjentikan jari, menggosokan tangan, menghentakan kaki dengan lantai, menepuk bangku, memukul gelas dengan stik, memukul piring dengan sumpit, dan bunyi bunyi yang dihasilkan suara, membentuk pola ritme dan melodi.

Penggubahan lagu dilakukan dengan penelaahan melodi dan liriknya, menggubah melodi berdasar motive seperti motive sekuens, repetisi dan imitasi, membentuk kalimat musik, dan membuat lagu pendek berstruktur A-B-A. A-A-B-B dan variasinya.

Kompetensi mengaransemen lagu dicapai dengan menyusun suatu karya yang digubah dengan menambah atau mengurangi beberapa unsur music dalam suatu karya. Karya yang dihasilkan oleh partisipan adalah dengan cara:

a. Memberikan ornament pada melodi.

b. Merubah pola akor yang semula sederhana menjadi lebih kompleks, pada karya yang semula mempergunakan akor I, IV, V, I menjadi I- I7-IV- V- V7-I.

c. Merubah pola irama, yang semula pola irama degung pada lagu manuk Dadali dirubah menjadi birama 4/4 dengan 
tempo andante dalam metrum musik Barat.

d. Merubah variasi pada lagu Panon Hideung yang semula berbirama $4 / 4$ dengan tempo andante dirubah menjadi pola musik rock dengan tempo moderato.

e. Merubah pola melodi dengan membuat variasi variasi, augmentasi dan diminuisi.

Penyempurnaan model mengajar yang ditemukan adalah: pada situasi awal, para peneliti banyak berorientasi pada penguatan kompetensi HOTS yang diberikan melalui kompetensi musik Barat, tetapi, perjalanan proses penelitian mengharuskan para peneliti untuk menindak lanjuti fakta factual, bahwa masyarakat pendidik musik banyak yang berlatar belakang pendidikan musik tradisi Sunda, sehingga materi workshop bergeser dari secara keseluruhan musik Barat dibagi menjadi dua area disiplin musik, yaitu pemberian penyusunan aransemen dan komposisi musik yang memiliki warna tradisi Sunda serta aransemen dan komposisi musik tradisi Barat.

Tujuan pengajaran musik untuk menerapkan High Order Thinking Skill. Pendekatan pengajaran yang ditemukan untuk mencapai High Order Thinking Skill, adalah apresiasi, selalu aktif, discovery inquiry ketika partisipan mencoba bereksplorasi bunyi dengan kecakapan komunikasi antara instruktur dan sesama partisipan, cooperative learning ketika bekerja sama berkreasi karya ansambel melalui kecakapan kolaboratif dan berpikir kritis dan kreatif serta bertindak kreatif selalu mewarnai seluruh kegiatan workshop yang dilaksanakan. Lingkungan Belajar memerlukan tempat yang cukup luas untuk bereksplorasi bunyi dan untuk menyusun aransemen serta komposisi.

Sarana dan prasarana yang dibutuhkan disesuaikan untuk mencapai kompetensi menganalisis, mengevaluasi dan berkreasi musik, serta kompetensi mengajarkan musik melalui kecakapan $\mathrm{C} 4$, aspek menganalisis musik, C5 aspek mengevaluasi aransemen dan karya musik, dan C6 aspek berkreasi musik. Prototype model mengajar yang ditemukan:

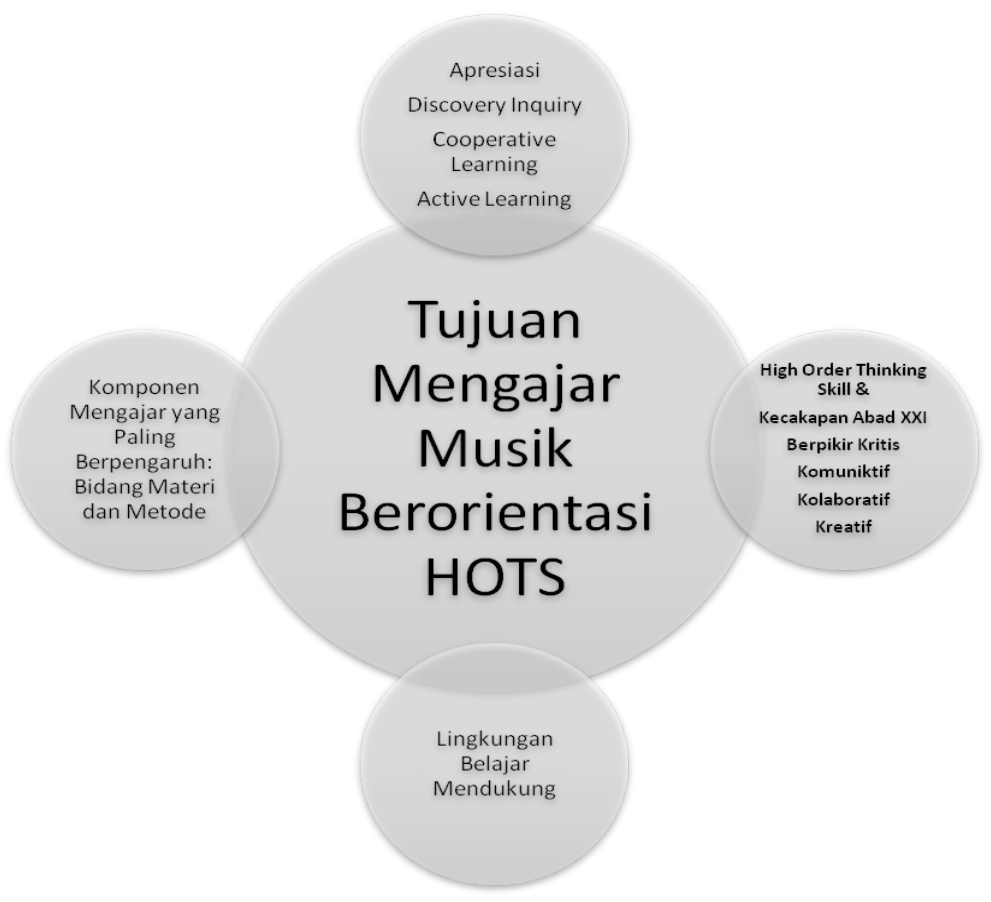

Gambar 1. Prototype Model Mengajar Musik Berorientasi HOTS (yang ditemukan) 
Metode yang secara umum digunakan saat partisipan praktek mengajar (music peer teaching) adalah metode ceramah, tanya jawab saat terdapat problematika yang dihadapi partisipan yang berperan sebagai siswa, praktek musik, dan eksplorasi bunyi serta uji coba (eksperimen) penerapan bunyi saat berkreasi musik ritmik dan menggubah lagu.

Materi yang diberikan sebagai bahan ajar adalah materi musik Barat dan tradisi Sunda, sesuai dengan latar belakang kompetensi mengajar guru musik. Aspek LOTS menuju HOTS yang paling banyak dilakukan partisipan saat mengajar musik adalah kegiatan mengamati dan menyimak musik melalui apresiasi (LOTS), praktek musik (LOTS), berpikir kritis dan kreatif saat menganalisis musik yang akan di terapkan (HOTS), dan kinerja kreativitas musik (HOTS).

Sintax mengajar yang ditemukan dan dilaksanakan oleh para partisipan secara umum, diawali dengan pengarahan informasi untuk memperkenalkan materi yang diberikan dengan kegiatan apresiasi, melakukan tanya jawab berdasar problematika yang dialami partisipan yang berperan sebagai siswa dengan merangsang berpikir kritis dan menghasilkan pemahaman dari proses berpikir kritis, praktek musik baik berupa musik ritmik atau pengolahan melodi dan bentuk musik, menganalisis apa yang dimainkan, menganalisis elemen musik yang dihasilkan, mempertanyakan keunggulan dan kekurangan setiap praktek musik yang dilaksanakan dan berakhir dengan kegiatan kreasi musik dari hasil pengolahan musik baik ritmik ataupun melodic.

\subsection{Pembahasan}

Dari hasil penelitian tampak bahwa para partisipan penelitian mengalami kejelasan menerapkan proses mengajar berorientasi HOTS dengan melaksanakan tahapan HOTS saat mereka melaksanakan proses mengajar music. Karena HOTS telah mejadi keniscayaan pencapaian pembelajaran dewasa ini. Sheldon \& DeNardo (2005:40) "Higher-order thinking is often a keyobjective in many education-all circumstances".

Proses mengajar musik yang berorientasi HOTS memerlukan kegiatan yang memicu ketrampilan berolah kreatif dalam kegiatan mengajar musik, dan hal ini dapat dilakukan melalui kegiatan aransemen dan komposisi musik. Bahkan di Inggris raya, telah terjadi perubahan radikal untuk para guru komposisi music agar mengajar dengan kreatif. Berkley (2004:240) "The radical changes to the UK music curriculum since the pioneering work of the composer-teachers in the creativity movement". Keativitas musik merupakan salah satu kegiatan kulminasi pencapaian HOTS. Sehingga untuk mencapianya merupakan suatu keniscayaan. Kusuma, Rosidin, Abdurrahman, \& Suyatna, (2017) affirmed "High order thinking skill is need the creative learning. Music education which appropriate with High order thinking skill are need creative music application that is music arrangement and composing". Demikian juga dengan kegiatan aransemen music diperlukan untuk memperkuat kreativitas, yang merupakan kulminasi pencapaian HOTS. Music arrangement is important to support creative process (Berkley, 2004; Spencer, 2013). 


\section{SIMPULAN}

Penerapan model mengajar musik berorientasi HOTS bagi guru SMA dan SMK, menghasilkan

1. Prototype model Mengajar Musik berorientasi HOTS

2. Kompetensi menerapkan proses LOTS menuju HOTS dalam kegiatan mengajar music

3. Kompetensi menyusun pola ritme dalam membentuk musik ritmik

4. Kompetensi mengaransemen lagu

5. Kompetensi menggubah Lagu

Tahapan pengajaran musik yang ditemukan dan secara umum dilaksanakan oleh partisipan penelitian:

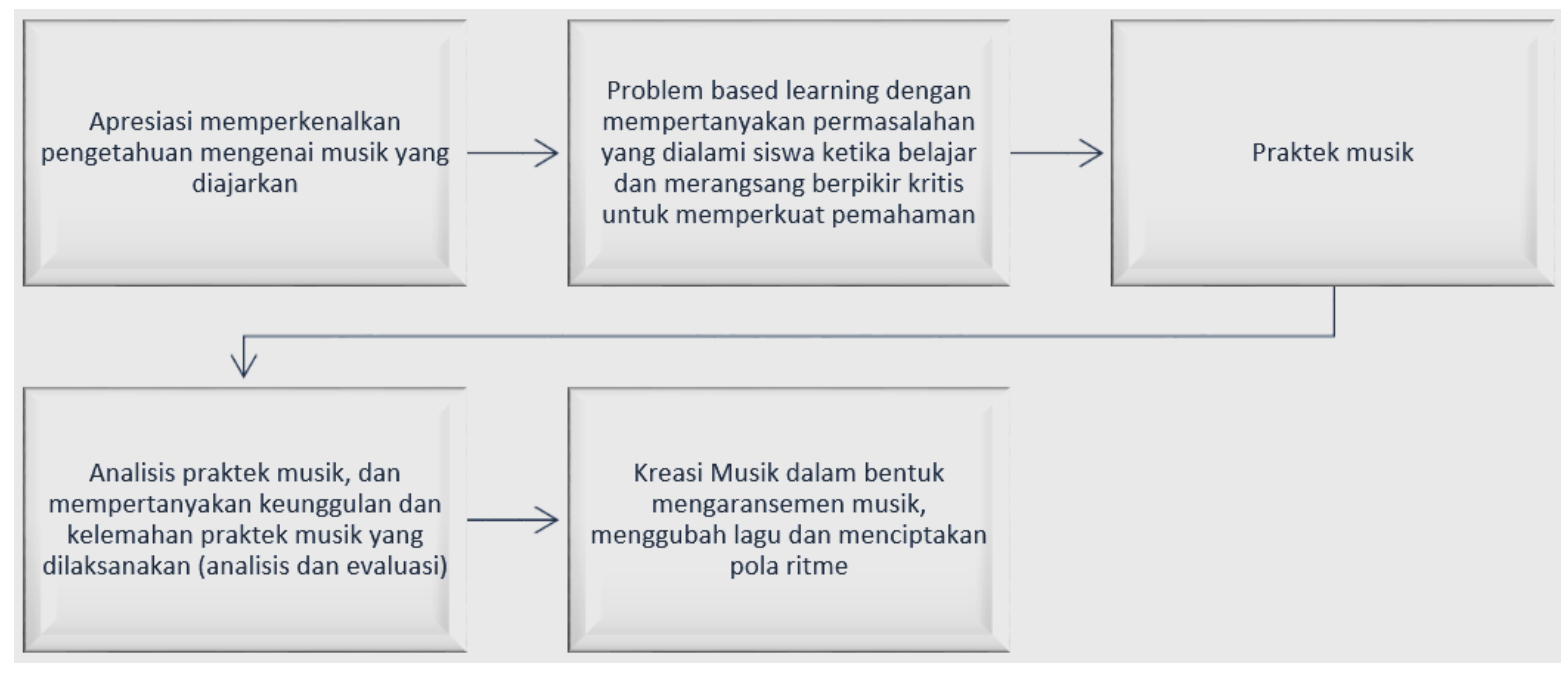

Diagram 4. Temuan Syntax Mengajar

Dari temuan tahapan mengajar yang dilaksanakan oleh partisipan, tampak bahwa kegiatan apresiasi memiliki kekuatan untuk mengenalkan atau memberi pengetahuan pada siswa, yang dilanjutkan dengan belajar berbasis masalah. Temuan selanjutnya, adalah menyatunya proses analisis musik dan evaluasi musik yang dipraktekan siswa (penerapan), dan akhirnya bermuara pada kreativitas musik, yang dibuktikan dengan kegiatan mengolah pola ritme, dan melodi untuk menciptakan kreasi musik baru.

Tujuan penelitian untuk membekali partisipan dengan kompetensi mengajar musik berorientasi HOTS, berhasil dilaksanakan dengan baik, dengan hasil penelitian, seluruh partisipan mengajar teman sejawatnya yang berperan sebagai siswa menghasilkan kreasi musik, memiliki kompetensi berpikir kritis, mampu berkomunikasi dalam bahasa musik, dan berkolaborasi menciptakan karya musik dalam kebersamaan, misalkan membuat kreasi melodi dalam bentuk dua suara yang secara reflek terproduksi dari musikalitas para partisipan yang berperan sebagai siswa.

Keunggulan penelitian ini menghasilkan kompetensi berpikir HOTS baik dalam berkreasi musik ataupun tatkala mengajar musik. Keterbatasan penelitian adalah proses mengajar masih dilaksanakan antara sesama guru, tidak diterapkan langsung secara kontekstual pada siswa dengan potensi dasar musik yang berbeda beda. 


\section{DAFTAR RUJUKAN}

Amiel, T., \& Reeves, T. C. (2008). Design-Based Research and Educational Technology: Rethinking Technology and the Research Agenda. Educational Technology \& Society (Vol. 11).

Berkley, R. (2004). Teaching composing as creative problem solving: conceptualising composing pedagogy. British Journal of Music Education, 21(3), 239-263. https://doi.org/10.1017/S026505170400587X

Collins, R. (2014). Skills for the 21st Century: teaching higher-order thinking. Curriculum \& Leadership Journal, 12(14).

Dhewa Kusuma, M., Rosidin, U., \& Suyatna, A. (2017). The Development of Higher Order Thinking Skill (Hots) Instrument Assessment In Physics Study. IOSR Journal of Research \& Method in Education, 7(1), $26-$ 32. https://doi.org/10.9790/7388-0701052632

Hashim, H., Ali, M. N., \& Shamsudin, M. A. (2017). Infusing High Order Thinking Skills (HOTs) through Thinking Based Learning (TBL) during ECA to enhance students interest in STEM. International Journal of Academic Research in Business and Social Sciences, 7(11), 1191-1199.

Henninger, J. C. (2018). The Nature of Expertise in Instrumental Music Settings: A Comparative Analysis of Common Elements Observed in Band Rehearsals and Applied Lessons. Journal of Band Research, 53(2), 48 .

King, F., Goodson, L., \& Rohani, F. (2010). Higher Order Thinking Skills. Retrieved from www.cala.fsu.edu

Kokkidou, M. (2013). Critical Thinking and School Music Education: Literature Review, Research Findings, and Perspectives. Journal for Learning through the Arts, 9(2), 1-16.

Kusuma, M. D., Rosidin, U., Abdurrahman, A., \& Suyatna, A. (2017). The Development of Higher Order Thinking Skill (Hots) Instrument Assessment In Physics Study. IOSR Journal of Research \& Method in Education (IOSRJRME), 07(01), 26-32. https://doi.org/10.9790/7388-0701052632

Mohd Tajudin Assoc, ain, \& Chinnappan, M. (2016). The Link between Higher Order Thinking Skills, Representation and Concepts in Enhancing TIMSS Tasks. International Journal, 9(2), 199-214. https:// doi.org/10.12973/iji.2016.9214a

Nalova, E. M., \& Shalanyuy, K. R. (2017). Teaching Practice and the Development of Higher Order Thinking Skills in Secondary School Students in the North West Region of Cameroon. European Journal of Education Studies, 0(0), 148-159.

Ping, O. W., Ahmad, A., Adnan, M., \& Hua, A. K. (2017). Effectiveness of higher order thinking skills (HOTS) based i-Think map concept towards primary students. In AIP Conference Proceedings (Vol. 1847, p. 030009). AIP Publishing LLC. https://doi.org/10.1063/1.4983886

Sheldon, D. A., \& DeNardo, G. (2005). Comparisons of Higher-Order Thinking Skills among Prospective Freshmen and Upper-Level Preservice Music Education Majors. Journal of Research in Music Education, 53(1), 40-50. https://doi.org/10.1177/002242940505300104

Shuler, S. C. (2011). Music Education for Life: The Three Artistic Processes--Paths to Lifelong 21st-Century Skills through Music. Music Educators Journal, 97(4), 9-13. https://doi.org/10.1177/0027432111409828

Small, A. R. (1987). Music Teaching and Critical Thinking: What Do We Need to Know? Music Educators Journal, 74(1), 46-49. https://doi.org/10.2307/3401236

Spencer, D. A. (2013). A creative and aural method to teach improvisation as a supplement to horn pedagogy for applied lesson instructors. University of Lowa. https://doi.org/10.17077/etd.3i0rda2y

Sulaiman, T., Muniyan, V., Madhvan, D., Hasan, R., Syrene, S., \& Rahim, A. (2017). Implementation of Higher Order Thinking Skills in Teaching Of Science: A Case Study in Malaysia. International Research Journal of Education and Sciences (IRJES), 1(1), 1-3. https://doi.org/10.1016/j.jclepro.2012.09.039

Topoğlu, O. (2014). Critical Thinking and Music Education. Procedia - Social and Behavioral Sciences, 116(1), 2252-2256. https://doi.org/10.1016/j.sbspro.2014.01.554

Widana, I. W. (2017). Higher Order Thinking Skills Assesment (HOTS). JISAE: Journal of Indonesian Student Assesment and Evaluation, 3(1), 32-44. https://doi.org/10.21009/JISAE.031.04

Wing, C. K., Piaw, C. Y., \& Chang, P. K. (2014). Effects of Aural-imitative and Aural-motivic Analyses on HigherOrder Thinking Skill and Creative Musical Product in Music Improvisation. Procedia - Social and Behavioral Sciences, 116, 5130-5134. https://doi.org/10.1016/J.SBSPRO.2014.01.1086 